\title{
Workshop Bedah Buku Ghazwul Fikri: Pola Baru Menyerang Islam di LIDMI Kota Kendari
}

\author{
Havis Aravik \\ Program Studi Perbankan Syariah STEBIS IGM Palembang \\ Email : havis@stebisigm.ac.id
}

\begin{abstract}
The Ghazwul Fikri book review workshop: A New Pattern of Attacking Islam at LIDMI Kendari City was carried out in collaboration between the Sekolah Tinggi Ekonomi dan Bisnis Syariah (STEBIS) and the Lingkar Dakwah Mahasiswa Indonesia (LIDMI) Kendari City which was held in three sessions, starting with 28 November, 9 December and 23 December 2020. The purpose of this activity is to provide understanding and knowledge about various wars of thought (Ghazwul Fikri) that can influence Muslim religious beliefs, so that they can deviate from the purity of religious teachings. This activity uses material presentation methods via zoom meetings, guidance and evaluation. The result of this workshop activity is that Muslims today face various threats and challenges from both internal and external to Muslims. The most serious threat is Ghazwul Fikri (war of thought), a new strategy used to destroy Islam with various models used such as fashion, food, fun, foundation, song, cinema, school, sex, and so on.
\end{abstract}

Keywords : Ghazwul Fikri, LIDMI Kota Kendari, STEBIS IGM

\begin{abstract}
Abstrak
Kegiatan Workshop bedah buku Ghazwul Fikri: Pola Baru Menyerang Islam di LIDMI Kota Kendari dapat terlaksana atas kerjasama antara Sekolah Tinggi Ekonomi dan Bisnis Syariah (STEBIS) Indo Global Mandiri dengan Lingkar Dakwah Mahasiswa Indonesia (LIDMI) Kota Kendari yang dilaksanakan dalam tiga session, di mulai tanggal 28 November, 9 Desember dan 23 Desember 2020. Tujuan dari kegiatan ini adalah untuk memberikan pemahaman dan pengetahuan tentang berbagai perang pemikiran (Ghazwul Fikri) yang dapat memengaruhi keyakinan beragama umat Islam, sehingga dapat melenceng dari kemurnian ajaran agama. Kegiatan ini menggunakan metode presentasi materi via zoom meeting, bimbingan dan evaluasi. Adapun hasil dari kegiatan workshop ini adalah bahwa umat Islam hari ini menghadapi berbagai ancaman dan tantangan baik dari internal umat Islam maupun dari eksternal umat Islam. Ancaman paling serius adalah Ghazwul Fikri (perang pemikiran) sebuah strategi baru yang digunakan untuk menghancurkan Islam dengan berbagai model yang dipakai seperti fashion, food, fun, foundation, song, sinema, school, sex, dan sebagainya.
\end{abstract}

Kata Kunci: Ghazwul Fikri, LIDMI Kota Kendari, STEBIS IGM 


\section{Pendahuluan}

Salah satu tema krusial yang jarang diangkat dalam khazanah pemikiran Islam di Indonesia khususnya adalah Ghazwul Fikri atau perang pemikiran. Tema ini tidak familiar bila dibandingkan tema-tema keislaman lainnya seperti tauhid, munakahat, muamalah, ushuluddin, fiqh, kalam dan lain sebagainya. Ghazwul fikri merupakan strategi terbaru musuh-musuh Islam dimana menyerang Islam tidak lagi menggunakan senjata, berhadapan (face to face) melainkan menggunakan pemikiran. Sebagaimana pepatah menyatakan bila ingin menghancurkan Islam, hancurkan generasi muda, bila ingin menghancurkan generasi muda, hancurkan akhlak.

Kehancuran akhlak merupakan salah satu tujuan utama dari Ghazwul Fikri. Oleh karena itu, perlu dilakukan pendampingan dan sosialisasi lebih dalam tentang masalah tersebut kepada masyarakat agar tidak terjadi salah pemahaman dan sudut pandang terhadap masalah tersebut. Sekaligus dapat menjadi filter dalam menghadapi berbagai sarana-sarana dipakai dan ideologi-idelogi yang ada dibelakangnya.

Berangkat dari itu, maka Lidmi Kota Kendari mengadakan workshop bedah buku Ghazwul Fikri: Pola Baru Menyerang Islam bekerjasama dengan Tim Pengabdian Masyarakat STEBIS IGM Palembang dengan tujuan untuk memberikan pengetahuan dan pemahaman tentang Ghazwul Fikri dengan berbagai motivasi-motivasi besar yang dibawah serta pengaruhnya terhadap perkembangan ilmu pengetahuan dan teknologi sekarang.

\section{Metode Pengabdian}

Pengabdian masyarakat ini dilaksankan dalam bentuk workshop Beda Buku Ghawzul Fikri: Pola Baru Menyerang Islam yang diselenggarakan Lingkar Dakwah Mahasiswa Indonesia (LIDMI) Kota Kendari dan metode pemaparan materi via zoom meeting, bimbingan dan tanya jawab interaktif dengan peserta secara langsung yang dilakukan sebanyak tiga session. Sesion pertama dengan tema Strategi Barat Menghancurkan Akhlak Generasi Islam yang dilaksanakan pada tanggal 23 November 2020 jam 20.30 WITA. Sesion kedua dengan tema Ideologi-Ideologi Perusak Islam; O Sepilis yang dilaksanakan pada 9 Desember 2020 pada jam 20.30 WITA. Sesion ketiga dilaksanakan pada 23 Desember 2020 pada jam 20.30 WITA dengan tema Sisi Gelap Feminisme, Utilitarianisme dan Positivisme, dengan peserta dari berbagai daerah di Indonesia, baik dari Indonesia bagian Barat, Indonesia bagian Tengah maupun Indonesia bagian Timur.

Kegiatan ini bertujuan antara lain: (1) memberikan pemahaman kepada peserta workshop tentang bahaya Ghazwul Fikri dalam kehidupan sehari-hari. (2) memperkenalkan kepada peserta workshop istilah-istilah dalam Ghazwul Fikri yang marak di era digital sekarang ini. (3) memberikan pencerahan kepada peserta workshop tentang keharusan untuk memahami Ghazwul Fikri mulai metode, sarana-sarana serta ideologi-ideologi yang menyertainya dan cara efektif mengantisipasi dan memfilter agar tidak menjadi bagian di dalamnya. Sedangkan manfaat yang diharapkan dari kegiatan workshop ini adalah: (a) peserta workshop diharapkan mampu memahami secara baik dan benar Ghazwul Fikri baik dari pengertian, sejarah, metode, dan sarana-sarananya, (b) peserta diharapkan memahami ideologi-ideologi yang dibawa Ghazwul Fikri seperti orientalisme, pluralism, feminisme, sekularisme, liberalisme, utilitarianisme dan positivisme.

Prosedur kegiatan pengabdian masyarakat dilakukan dengan tahapan sebagai berikut: Pertama, membalas surat yang disampaikan pengurus LIDMI Kota 
Kendari prihal permohonan permintaan menjadi pembicara bedah buku Ghazwul Fikri: Pola Baru Menyerang Islam. Kedua, membuat materi yang akan disampaikan pada acara bedah buku. Ketiga, ikut menyebarkan atau mensosialisasikan acara di lini-lini sosial media seperti Whatshap, facebook, Instagram, dan sebagainya. Keempat, membuat laporan pengabdian masyarakat. Kelima, desiminasi.

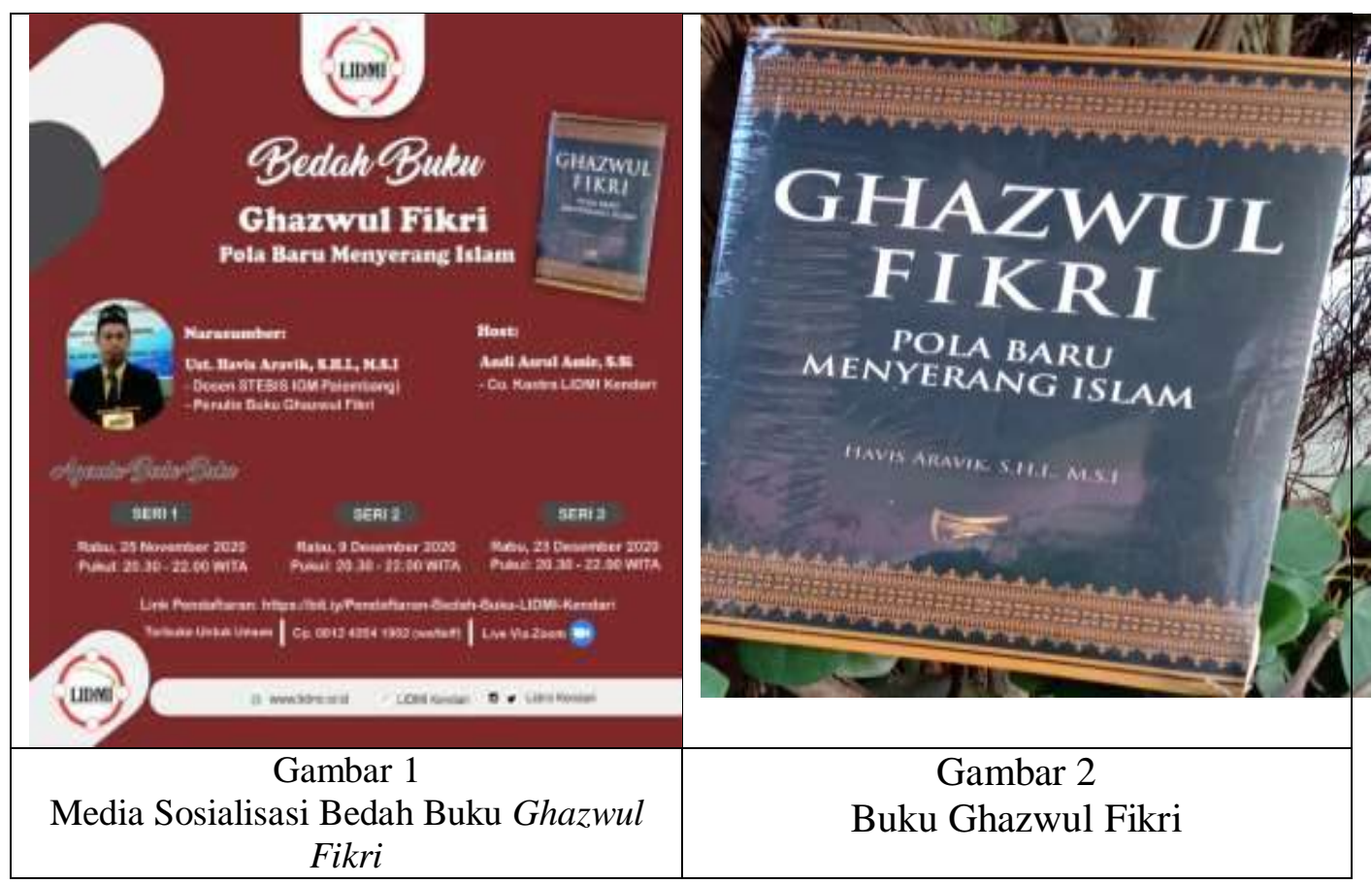

\section{Hasil dan Pembahasan}

Kegiatan Workshop bedah buku Ghazwul Fikri: Pola Baru Menyerang Islam dilaksanakan sebanyak tiga kali pertemuan dengan peserta pada session pertama sebanyak 50 orang. Session kedua dengan jumlah peserta sebanyak 48 orang orang, dan session ketiga sebanyak 62 orang yang terdiri atas berbagai masyarakat dengan berbagai profesi dari berbagai daerah di Indonesia dimulai dari tanggal 23 November, 9 Desember, dan 23 Desember melalui via Zoom Meeting. Dalam kegiatan ini, penulis menyampaikan pentingnya mengetahui dan memahami Ghazwul Fikri sebagai salah satu cara baru menyerang Islam, yang dilakukan tidak menggunakan senjata, vis a vis, head to head melainkan lewat kata-kata atau pemikiran. Adapun materi bedah buku lengkapnya sebagai berikut:

1. Gambaran Umum Ghazwul Fikri

Secara etimologis Ghazwul Fikri berasal dari kata "Ghazwul" artinya perang, serangan, serbuan, dan invasi. Sedangkan "Fikr" adalah pemikiran. Jadi ketika kata Ghazwul dan Fikri digabung menjadi satu maka artinya adalah perang pemikiran. Sedangkan secara terminologis Ghazwul Fikri bermakna penyerangan dengan berbagai cara terhadap umat Islam guna mengeluarkan mereka dari agamanya atau meninimal menjauhkan umat Islam dari nilai-nilai ajaran ilahiah.

Ghazwul Fikri sering juga disebut dengan perang intelektual, perang kecerdasan, perang otak, perang non konvensional atau perang tak terlihat (proxy war). Di mana senjata yang dipakai bukan pedang, pistol, tombak, keris, ataupun bom. Melainkan pemikiran, tulisan, ide-ide, teori, argumentasi, propaganda, agitasi, dialog, dan perdebatan yang bersifat defensif maupun opensif. Jadi 
Ghazwul Fikri merupakan perang yang tidak menumpahkan darah, tidak menghancurkan gedung-gedung, sekolah-sekolah, rumah-rumah ibadah, menghancurkan wilayah, dentingan senjata dan desingan peluru. Namun, daya ledak dan daya rusak lebih hebat dari perang-perang konvensional (Aravik, 2015).

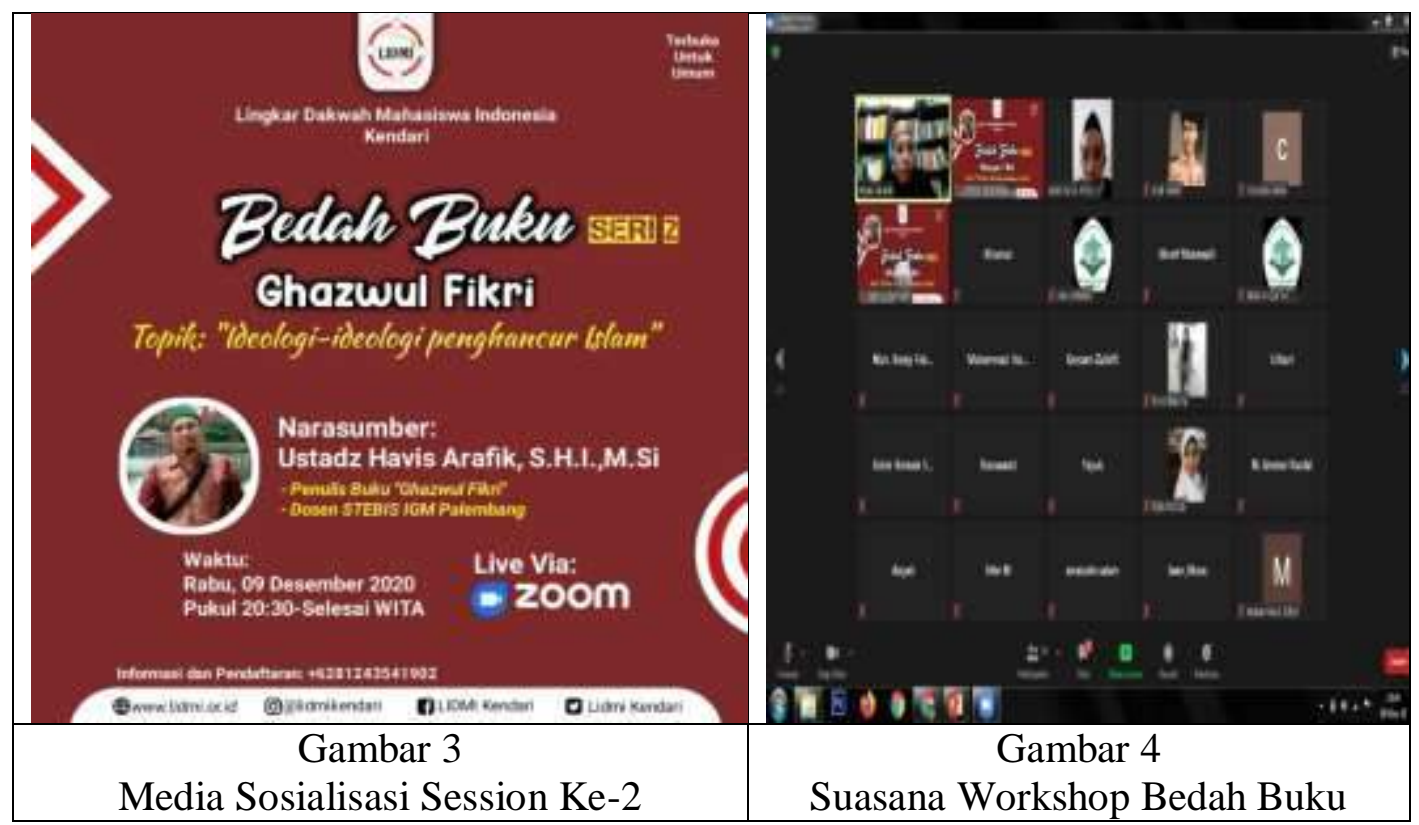

2. Sarana-Sarana Ghazwul Fikri

Guna memastikan kesuksesan Ghazwul Fikri, setidaknya ada empat cara yang dilakukan, yaitu: Pertama, Tasykik, yaitu menimbulkan keragu-raguan dan pendangkalan dalam jiwa kaum muslimin terhadap agamanya. Kedua, Tasywih, yaitu pengaburan. Caranya dengan penggambaran buruk tentang Islam untuk menghilangkan kebanggaan kaum muslimin terhadap Islam. Ketiga, Tadzwiib, yaitu pelarutan, pencampuradukan atau talbis antara pemikiran dan budaya Islam dengan pemikiran dan budaya Jahiliyyah. Keempat, Taghrib, atau westernisasi (pembaratan), yaitu mendorong kaum muslimin untuk menyenangi dan menerima pemikiran, kebudayaan, gaya hidup dan apa saja yang datang dari Barat. Selain itu, memanfaatkan berbagai saluran baik elektronik maupun cetak untuk menyebarkan berbagai sarana-sarana yang dikenal dengan istilah $4 \mathrm{~F}$ dan $5 \mathrm{~S}$. Yakni: Fashion, fun, food, foundation, song, sinema, school, sex, dan sport. Kesemuanya itu bertujuan antara lain: (1), Ifsad al-Akhlak, Perusakan akhak (QS. [61]:8, [9]: 32). (2), Tahzhim al-Fikrah, penghancuran pemikiran (QS. An-Nisa' [4]: 60). (3), Idzabah al-Syakhsiyyah, melunturkan atau melarutkan kepribadian (QS. [68]: 6, An-Nisa' [4]: 89). (4), Al-Riddah, penumbangan aqidah. (5), al-wala lil kafirin, loyalitas kepada kaum kafir (QS. Al-Maidah [5]: 51) (Aravik, 2015).

\section{Ideologi-Ideologi Ghazwul Fikri}

Ada berbagai ideologi yang secara tersurat dan tersirat berpotensi menjauhkan umat Islam dari agamanya, antara lain: Pertama, sekularisme. Sekularisme merupakan gerakan dalam masyarakat yang mencoba memisahkan urusan luar dunia dari dunia ini. Digagas oleh George Jacob Holyoke pada tahun 1864 M. Sekularisme beranggapan, bahwa kehidupan duniawi ini adalah mutlak dan terakhir. Tiada lagi kehidupan sesudahnya, yang biasanya oleh agama disebut sebagai Hari Kemudian, Hari Kebangkitan dan sebagainya. 
Ideologi Sekularisme termasuk ke dalam Madzahib Haddamah, yang bertujuan untuk memisahkan antara Agama dengan kehidupan dan segala aspekaspeknya, Juga bertujuan untuk mendirikan kehidupan tanpa Agama dan menjauhkannya serta memusuhinya seperti kaum komunis (Ismail, 2014). Berkat konsep dan pandangan seperti itu, Majelis Ulama Indonesia (MUI) telah menetapkan haramnya sekularisme. Karena memisahkan urusan duniawi dari agama, sedangkan hubungan sesama manusia diatur hanya dengan berdasarkan kesepakatan sosial (Aravik, 2015).

Kedua, Pluralisme Agama, yakni sebuah ideologi yang menyakini bahwa semua agama adalah jalan yang sama-sama sah menuju Tuhan yang sama. Jadi, menurut penganut ideologi ini, semua agama adalah jalan yang berbeda-beda menuju Tuhan yang sama. Atau mereka menyatakan bahwa agama adalah persepsi relative terhadap Tuhan yang mutlak, sehingga - karena relativitasnya maka setiap pemeluk agama tidak boleh mengklaim dan menyakini, bahwa agamanya sendiri yang benar atau lebih baik dari agama lain; atau mengklaim bahwa hanya agamanya sendiri yang benar.

Setidaknya pluralisme agama dapat dibagi menjadi tiga kategori, humanisme sekuler, teologi global, dan sinkretisme. Ketiga kajian ini ujung-ujungnya berakhir pada muara yang sama, yaitu melegitimasi yang setara kepada semua agama (semua aliran dan ideologi) yang ada, agar dapat hidup berdampingan. Puncaknya, Pluralisme Agama ingin mengantarkan manusia kepada sebuah kesepakatan bahwa semua agama merupakan manifestasi-manifestasi dan bentukbentuk yang beragam dari hakikat esoterik yang tunggal. Dari sudut pandang ini dimensi esoterik merupakan sesuatu yang absolut dan dimensi eksoterik bersifat relatif agar agama-agama dapat berkoeksistensi satu sama lainnya (Khaerurrozikin, 2015)

Ketiga, Liberalisme merupakan sebuah ideologi yang memahami nash-nash agama (al-Qur'an dan Hadits) menggunakan akal pikiran yang bebas atau hanya menerima doktrin-doktrin agama yang sesuai dengan akal pikiran semata. Secara filosofis, liberalisme merupakan tata pemikiran yang bebas karena manusia mampu berpikir dan bertindak sesuai dengan apa yang diinginkannya (Irawan, 2018). Ideologi ini sangat berbahaya bagi Islam sehingga termasuk salah satu yang dikhawatirkan Yusuf Qardhawi melanda generasi muda Islam. Liberalisme termasuk format pemikiran yang mencakupi segenap aspek kehidupan manusia termasuk pendidikan, agama, sosial dan sebagainya. Ia berpegang kepada konsep rasional, keterbukaan dan kebebasan intelektual (Norsaleha Mohd. Salleh, Noor Hafizah Mohd. Haridi, Phayilah Zakaria, Juzlinda Mohd. Ghazali, 2017). Karena sangat berbahaya, maka Majelis Ulama Indonesia (MUI) dalam Munasnya yang ke-7 pada 25-29 Juli 2005, di Jakarta, telah menetapkan fatwa tentang haramnya Liberalisme. Bahkan atas nama keyakinan liberalisme, seseorang menyakini dapat melakukan hubungan seksual sebebas-bebasnya, orang bebas minum dan makan apa saja, orang berpakaian seenak nafsunya, padahal itu semua adalah kerusakan dan membahayakan tidak hanya bagi dirinya melainkan orang lain dan alam (Aravik, 2015)..

Keempat, utilitarianisme merupakan suatu ideologi yang didirikan Jeremy Betham (1748-1832) dan Jhon Stuart Mill (1806-1873) yang menyatakan bahwa the greatest happiness of the greatest number atau kebahagiaan adalah segalanya.

Utilitarianisme merupakan bagian dari salah satu pembahasan filsafat moral, khususnya teleologi (Saepullah, 2020). Ideologi ini berbahaya karena cenderung akan menghalalkan segala cara untuk mendapatkan kebahagiaan yang di damba- 
dambakan. Sedangkan dalam Islam setiap manusia di tuntut untuk ada dalam koridor aturan-aturan ilahiyah yang suci dan tidak boleh merugikan orang lain atas nama kebahagiaan yang ingin didapatkan.

Kelima, Positivisme merupakan ideologi yang menjadi bagian dari kerangka berfikir materialisme dan menggunakan tolak ukur kebenaran rasional, empiris, eksperimental serta terukur. Sesuatu dikatakan benar apabila memenuhi kriteria ini. Jelas, ukuran-ukuran ini tidak seluruhnya dapat digunakan untuk menguji kebenaran agama. Misalnya, bagaimana menyakini adanya surga dan neraka padahal secara empiris dan eksprimental tidak dapat dibuktikan keberadaannya. Positivisme pertama kali dikembangkan Auguste Comte (1798-1857) dalam konteks hokum, positivisme menjelma dalam bentuk positivisme hukum yang memandang perlu memisahkan secara tegas antara hukum dan moral (antara hukum yang berlaku dan hukum yang seharusnya, antara das sein dan das) yang tentu saja sangat berbahaya bagi ajaran Islam (Aravik, 2015).

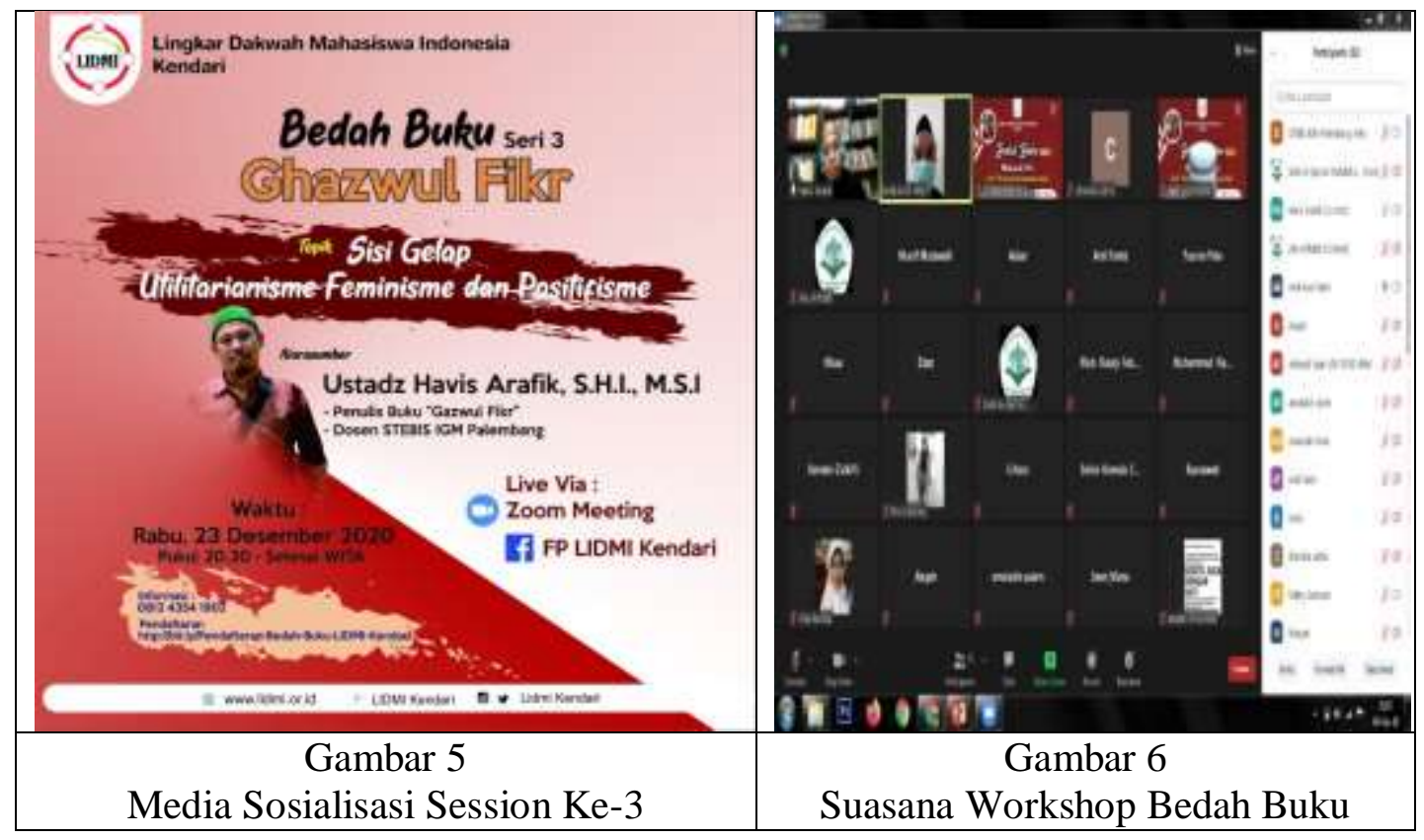

Akhirnya, Buku Ghazwul Fikri: Pola Baru Menyerang Islam mengajak merenungkan beberapa firman Allah SWT dalam Al-Qur'an berikut ini (Aravik, 2015):

Pertama, Surah Al-Baqarah [2] ayat 190.

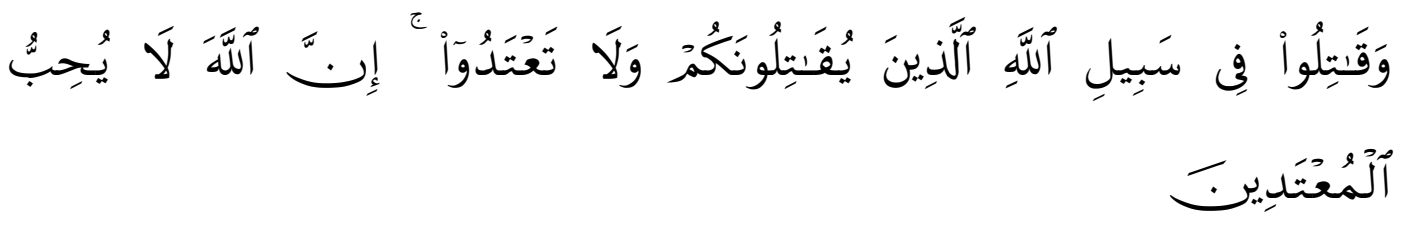

"Dan perangilah di jalan Allah orang-orang yang memerangi kamu, (tetapi) janganlah kamu melampaui batas, Karena Sesungguhnya Allah tidak menyukai orang-orang yang melampaui batas."

Kedua, Surah Ali-Imran [3] ayat 118-119 


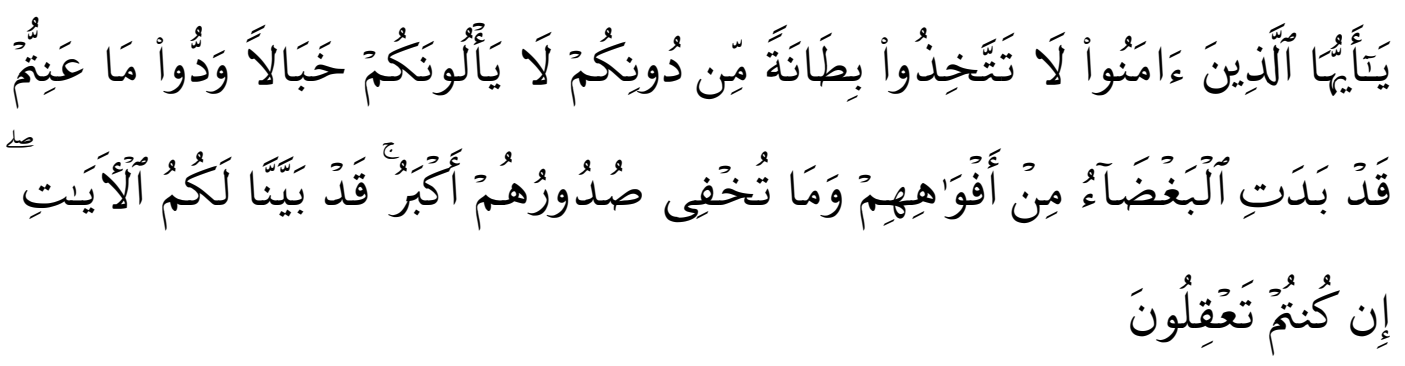

"Hai orang-orang yang beriman, janganlah kamu ambil menjadi teman kepercayaanmu orang-orang yang, di luar kalanganmu (karena) mereka tidak henti-hentinya (menimbulkan) kemudharatan bagimu. mereka menyukai apa yang menyusahkan kamu. Telah nyata kebencian dari mulut mereka, dan apa yang disembunyikan oleh hati mereka adalah lebih besar lagi. sungguh Telah kami terangkan kepadamu ayat-ayat (Kami), jika kamu memahaminya.

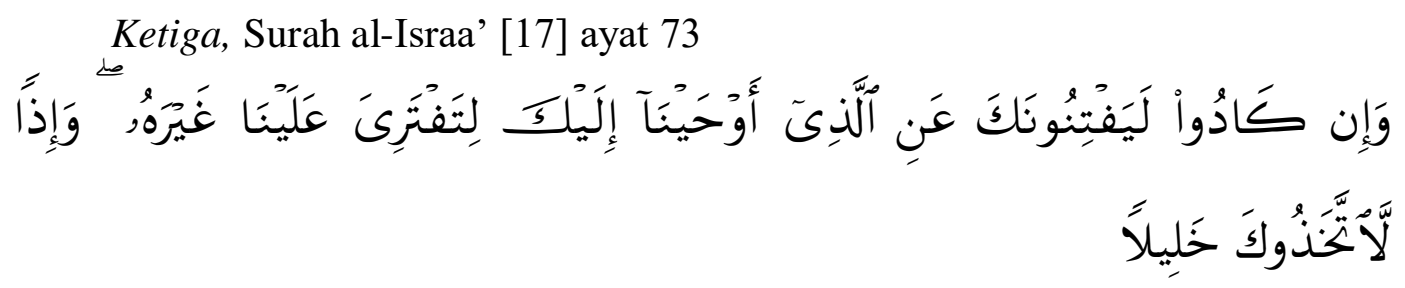

"Dan Sesungguhnya mereka hampir memalingkan kamu dari apa yang Telah kami wahyukan kepadamu, agar kamu membuat yang lain secara bohong terhadap Kami; dan kalau sudah begitu tentulah mereka mengambil kamu jadi sahabat yang setia."

Keempat, Surah Al-Baqarah [2] ayat 217
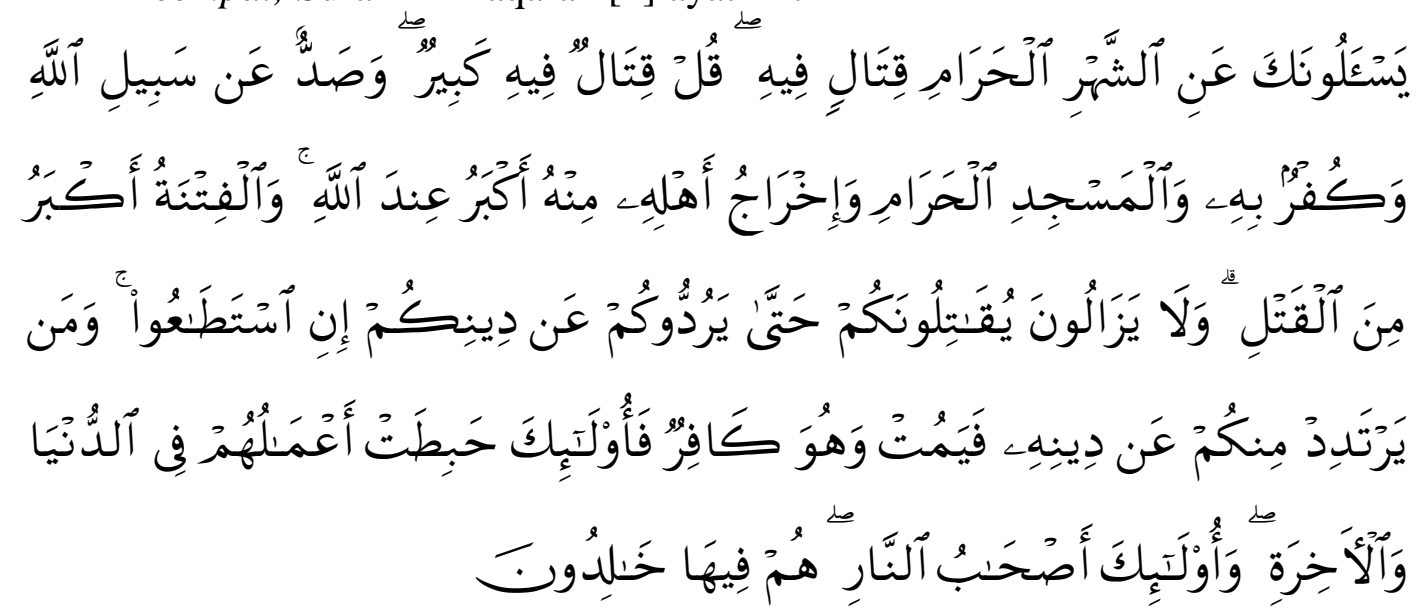

"Mereka bertanya kepadamu tentang berperang pada bulan Haram. Katakanlah: "Berperang dalam bulan itu adalah dosa besar; tetapi menghalangi (manusia) dari jalan Allah, kafir kepada Allah, (menghalangi masuk) Masjidilharam dan mengusir penduduknya dari sekitarnya, lebih besar (dosanya) di sisi Allah. dan berbuat fitnah lebih besar (dosanya) daripada membunuh. mereka tidak hentihentinya memerangi kamu sampai mereka (dapat) mengembalikan kamu dari agamamu (kepada kekafiran), seandainya mereka sanggup. barangsiapa yang murtad di antara kamu dari agamanya, lalu dia mati dalam kekafiran, Maka mereka Itulah yang sia-sia amalannya di dunia dan di akhirat, dan mereka Itulah penghuni neraka, mereka kekal di dalamnya. 
Kelima,Surah At-Taubah [9] ayat 32

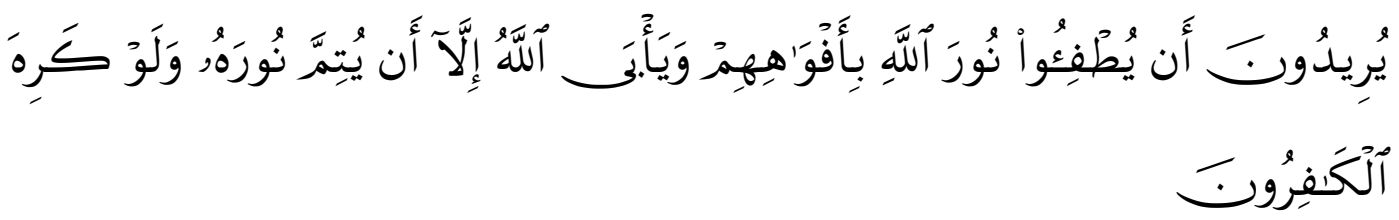

"Mereka berkehendak memadamkan cahaya (agama) Allah dengan mulut (ucapan- ucapan) mereka, dan Allah tidak menghendaki selain menyempurnakan cahayanya, walaupun orang-orang yang kafir tidak menyukai."

Keenam, surah al-Baqarah [2] ayat 120
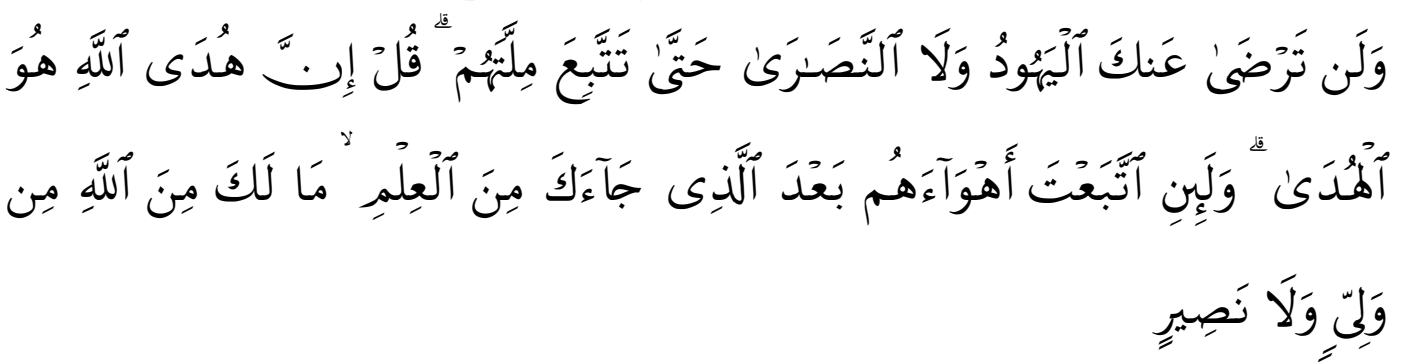

Orang-orang Yahudi dan Nasrani tidak akan senang kepada kamu hingga kamu mengikuti agama mereka. Katakanlah: "Sesungguhnya petunjuk Allah Itulah petunjuk (yang benar)". dan Sesungguhnya jika kamu mengikuti kemauan mereka setelah pengetahuan datang kepadamu, Maka Allah tidak lagi menjadi pelindung dan penolong bagimu.

\section{Simpulan}

Dari uraian kegiatan workshop Bedah Buku Ghazwul Fikri: Pola Baru Menyerang Islam dapat di ambil kesimpulan

1. Kegiatan workshop bedah buku Ghazwul Fikri: Pola Baru Menyerang Islam sangat bermanfaat bagi masyarakat, tidak hanya dapat memberikan pemahaman baru seputar tema yang dibahas, tetapi dapat menjadi khazanah pengetahuan yang dapat dipraktekkan dalam kehidupan sehari-hari.

2. Ghazwul Fikri merupakan kajian baru yang masih terasa asing bagi banyak orang. Oleh karena itu perlu dilakukan kajian-kajian serupa dengan format dan metode yang berbeda, sehingga dapat familiar dan populer dalam kajiankajian keagamaan Islam.

3. Ghazwul Fikri sudah masuk dalam berbagai saluran yang sering dinikmati masyarakat Islam setiap saat, baik melalui media cetak, elektronik maupun media-media lainnya dalam wujud fashion, fun, food, foundation, song, sinema, school, sex, dan sport. Untuk itu, perlu pemahaman yang cukup dan intens agar dapat memfilter itu semua sehingga tidak menjauhkan dari keyakinan agama. 


\section{Daftar Pustaka}

Aravik, H. (2015). Ghazwul Fikri: Pola Baru Menyerang Islam. NoerFikri Offset.

Irawan, I. (2018). Al-Tawassut waal-I'tidal: Menjawab Tantangan Liberalisme dan Konservatisme Islam. Afkaruna, 14(1), 49-74. https://doi.org/10.18196/aiijis.2018.0080.49-74

Ismail, M. S. (2014). Kritik Terhadap Sekularisme (Pandangan Yusuf Qardhawi). Kontekstualita, 29(1), 101-126.

Khaerurrozikin, A. (2015). Problem Sosiologis Pluralisme Agama di Indonesia. Kalimah, 13(1), 93. https://doi.org/10.21111/klm.v13i1.280

Norsaleha Mohd. Salleh, Noor Hafizah Mohd. Haridi, Phayilah Zakaria, Juzlinda Mohd. Ghazali, G. B. R. A. dan M. S. M. N. (2017). Liberalisme Dalam Pemikiran Belia Di Media Sosial (Liberalism Thought Among Youth On Social Media). Fuaduna: Jurnal Kajian Keagamaan Dan Kemasyarakatan, 2(1), 165-175.

Saepullah, A. (2020). Konsep Utilitarianisme John Stuart Mill: Relevansinya terhadap Ilmu-ilmu atau Pemikiran Keislaman. Aqlania: Jurnal Filsafat Dan Teologi Islam, $11(2)$, 243-261. https://doi.org/http://dx.doi.org/10.32678/aqlania.v11i2.2961 
Workshap Bedah Buku Ghazwul Fikri: Pola Baru Menyerang Islam di LIDMI Kota Kendari,

Havis Aravik 